\title{
VESTIR EL LECHO. UNA INTRODUCCIÓN AL AJUAR TEXTIL DE LA CAMA EN LA ESPAÑA DE LOS SIGLOS XV Y XVI \\ DRESSING THE BED. AN INTRODUCTION TO THE BEDDING IN SPAIN IN THE 15th AND 16th CENTURIES
}

Ana María Ágreda Pino* Universidad de Zaragoza

\section{Resumen}

El presente estudio se centra en los elementos textiles que conformaron los lechos de los inicios Edad Moderna, y en esencia constituye una aproximación a las características y usos del arte textil o del bordado en el ámbito doméstico a través de un objeto, la cama, en el que el tejido tuvo un papel esencial.

Palabras clave: España, cama, textil, bordado, espacio doméstico.

\section{Abstract}

This study is about the textiles in the beds of the Early Modern Age, and it is an approach to the characteristics and uses of art textile or embroidery at home, through the bed, because in the bed the tissue had an essential role.

Keywords: Spain, bed, textile, embroidery, interior design.

\section{Introducción}

La cama y su ajuar constituyen una buena muestra del amplio abanico de obras textiles usadas en la vivienda; de sus características decorativas o de los valores y funciones asignados al tejido. ${ }^{1}$

En sus orígenes la cama debió de ser más bien un funcional acopio de paja con elementos de abrigo, que se fueron haciendo más sofisticados paulatinamente. La cama nació como un conjunto de piezas textiles y los tejidos se mantuvieron como esencia y fundamento del lecho a lo largo de los siglos. En la Edad Media, la cama no se configura como un verdadero mueble, con una estructura de madera visible, sino que este armazón está cubierto por un

\footnotetext{
*E-mail: amagreda@unizar.es
} 
complejo ajuar textil, que refleja la riqueza y el rango de sus propietarios. ${ }^{2}$ Durante el siglo XVI, el trabajo de talla de la madera va siendo más refinado, pero los aditamentos textiles mantienen un papel primordial. El lecho desaparecía bajo las telas que lo cubrían ${ }^{3}$ y fue tal su importancia que el término cama podía significar simplemente el conjunto de las colgaduras, cortinas, cubiertas o almohadas. ${ }^{4}$ A pesar de ello, apenas se han estudiado las piezas textiles que conformaban estas camas. Sin duda contribuye a esta situación la ausencia casi total de obras conservadas. Resulta necesario recurrir a fuentes indirectas (documentales, literarias o gráficas), que presentan su propia complejidad, pero que son fundamentales a la hora de reconstruir el papel del textil en relación con el mobiliario y, por extensión, su función en los espacios domésticos.

El valor de algunos ajuares textiles de la cama era muy elevado. Una colgadura de cama de canequí blanco que perteneció al rey Felipe II, bordada con motivos vegetales y animales en seda matizada y oro, se tasó en 1.500 reales. ${ }^{5} \mathrm{La}$ cama era el objeto más caro que poseían las familias de clase media y en el caso de Holanda una cama con su paramento y cortinajes llegaba a alcanzar los 100 gulden, la misma cantidad con la que un comerciante rico podía adquirir una casa adecuada a su rango. ${ }^{6}$ La cama se convirtió en el bien más importante que podía legarse a los descendientes y el más valioso que aportaba la mujer al matrimonio. ${ }^{7} \mathrm{El}$ acondicionamiento de estas camas era un desembolso muy importante para los padres de la novia, por lo que en algunos casos se recurrió a la falsificación de la calidad de los aparejos textiles. Se intentaba que la vistosidad de las piezas supliese su deficiente naturaleza. Esta práctica, que se extendió a otros bienes de la dote, dio lugar a la aparición del término "engañayernos" o "ciegayernos", para definir un objeto de buena apariencia y poco valor que se utilizaba para deslumbrar y embaucar. ${ }^{8}$

\section{El ajuar textil de la cama}

Las camas, y específicamente las de mayor valor, como las llamadas "camas de campo", definidas por el Diccionario de Autoridades como un lecho "mui capaz y extendido", 9 estaban cubiertas por un ajuar textil muy complejo y con una terminología específica de lo más variado. Los cortinajes rodeaban por completo la cama y la separaban del espacio circundante. El mal llamado en nuestros días dosel es denominado en la documentación de la época paramento, en alusión a que se trata de una estructura y adorno que cubre la cama, ${ }^{10} \mathrm{o}$ también pabellón. ${ }^{11}$ La voz pabellón procedería del francés antiguo "paveillon" (tienda de campaña), que a su vez derivaría del latín "papilio-onis" (mariposa). Esta procedencia se explicaría por la posibilidad de establecer una similitud entre las alas de las mariposas y las telas de las tiendas, agitadas por el viento. Del sentido etimológico inicial, se pasaría a utilizar esta palabra para nombrar el conjunto de cortinajes y cielo que cubría el lecho. Covarrubias señala que el uso del vocablo pabellón para denominar el conjunto textil que rodea la cama se debió a que en sus inicios estas cubiertas del lecho se inventaron "para los que 
caminando habían de dormir en despoblado, adonde de ordinario suelen ser molestos los mosquitos y las mariposas, para defenderse de sus picaduras". En el Diccionario de Autoridades se dice que estas tiendas de campaña tendrían una forma redonda en su base y una remate en punta en la parte superior. ${ }^{12}$ Una apariencia que pudieron adquirir a su vez algunos cielos de cama, como puede verse en el retablo de la Anunciación del Museo del Prado pintado en 1559 por Juan Correa de Vivar o en la escena de la cámara nupcial de Herse de la serie de tapices dedicada a Los amores de Mercurio y Herse (ca. 1570), obra de Willen de Pannemaker ${ }^{13}$ y más tardiamente en El Nacimiento de la Virgen del mismo museo obra de Jusepe Leonardo (1642). De hecho, entre los bienes que pertenecían a don Alonso de Aragón, abad del Monasterio de Montearagón, se incluía en 1552 "un pabellon de tornasol de tafetán con un capirote de terciopelo verde con una franja del mesmo color del pabellon con su poma y cordon de hiladillo" y en el inventario de las colchas, almohadas y otros aparejos de cama que pertenecieron a Felipe II figura "un pabellón de tafetán blanco, pintado de colores..., con su capirote de tafetán azul bordado de oro de la China"14. El término capirote aludiría en estos casos a la terminación en punta del pabellón, ya que esta voz se utilizaba también para designar a una construcción en forma de cúpula o de capucha. ${ }^{15}$ Sin embargo, la parquedad de las fuentes impide aseverar con certeza si la voz pabellón haría referencia a un tipo específico de paramento, con una elevación apuntada en el centro. ${ }^{16}$

Los paramentos y pabellones se sostenían gracias a diversas estructuras de madera y otros materiales. En ocasiones, estos armazones eran visibles, con sus pilares o columnas, cornisas y remates más o menos complejos, pero con frecuencia los esqueletos sustentantes quedaban completamente ocultos por las telas que constituían las diferentes partes del baldaquino textil.

Elementos fundamentales de estos pabellones y paramentos eran las cortinas, que permitían rodear y cerrar el lecho. Hay noticias de la existencia de cortinajes en las camas desde el siglo XII. Su número era variable y en los inventarios se citan paramentos de dos a seis cortinas, aunque son más frecuentes los de cuatro. Las cortinas, también llamadas en ocasiones "toballolas", "corredizas", o "cortinas corredizas", podían diferenciarse por la posición que ocupaban. Entre las camas que pertenecieron a la reina Juana, se describe un lecho en el que se distingue entre la zona "costañera" o "costanera" es decir, la que se situaba en el costado o lado del lecho y la "caveçera", cada una con su respectivo paño o cortina. ${ }^{17} \mathrm{En}$ el inventario de los bienes del obispo de Urgel se menciona una cama con un "respaldero de raz", que podría ser la cortina o tejido que se colocaba en la cabecera del lecho. Wright llama a esta colgadura o cortina, "dorsal", por su posición en la zona del dorso o espalda de la cama y señala que podía tener una decoración diferenciada, con la inclusión del escudo de armas de la familia. ${ }^{18}$ La ornamentación especial de esta cortina de la cabecera sirvió para distinguirla de las demás y subrayar su posición singular y preeminente en el lecho. La utilización de tejidos tan ricos y costosos como el brocado, con su entrecruzamiento de hilos de seda y oro componiendo motivos vegetales, tal como aparece en la Anunciación (1455) 
del altar de Santa Columba de Rogier van der Weyden o en la escena del Nacimiento de la Virgen (c. 1470) obra de un pintor alemán conocido como Maestro de la vida de la Virgen, son indicios de la importancia concedida a esta zona del lecho. En otras ocasiones, esta cortina o paño de la cabecera se utilizaba para colgar pequeños espejos, formas solares o estelares, así como imágenes sagradas que tenían una función protectora, tal como se aprecia en la Anunciación representadas por van der Weyden $(, 1440)$ o van Cleve (c. 1525), así como en las correspondientes al Nacimiento de María de Jan de Beer (1520) o al Nacimiento de San Juan Bautista de Juan de Flandes (1499) y Jean de Fouquet (Libro de Horas de Étienne Chevalier, 1452-1460).

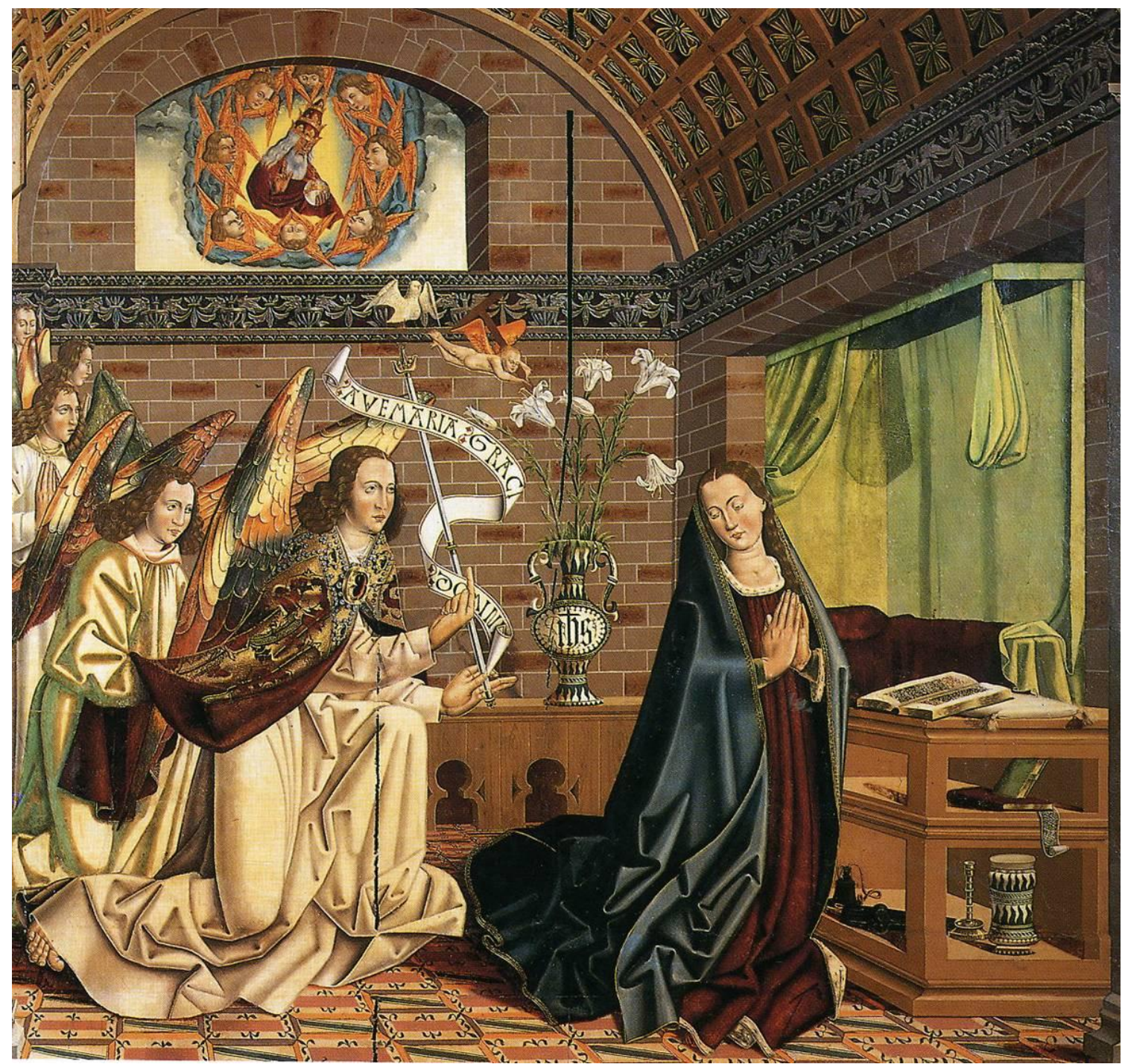

Fig. 1. Escena de la Anunciación que ilustra las características de una cama con paramento. Alonso de Sedano, Armario de las reliquias de la catedral de Burgos. Hacia 1495. (Fotografía de René Payo) 


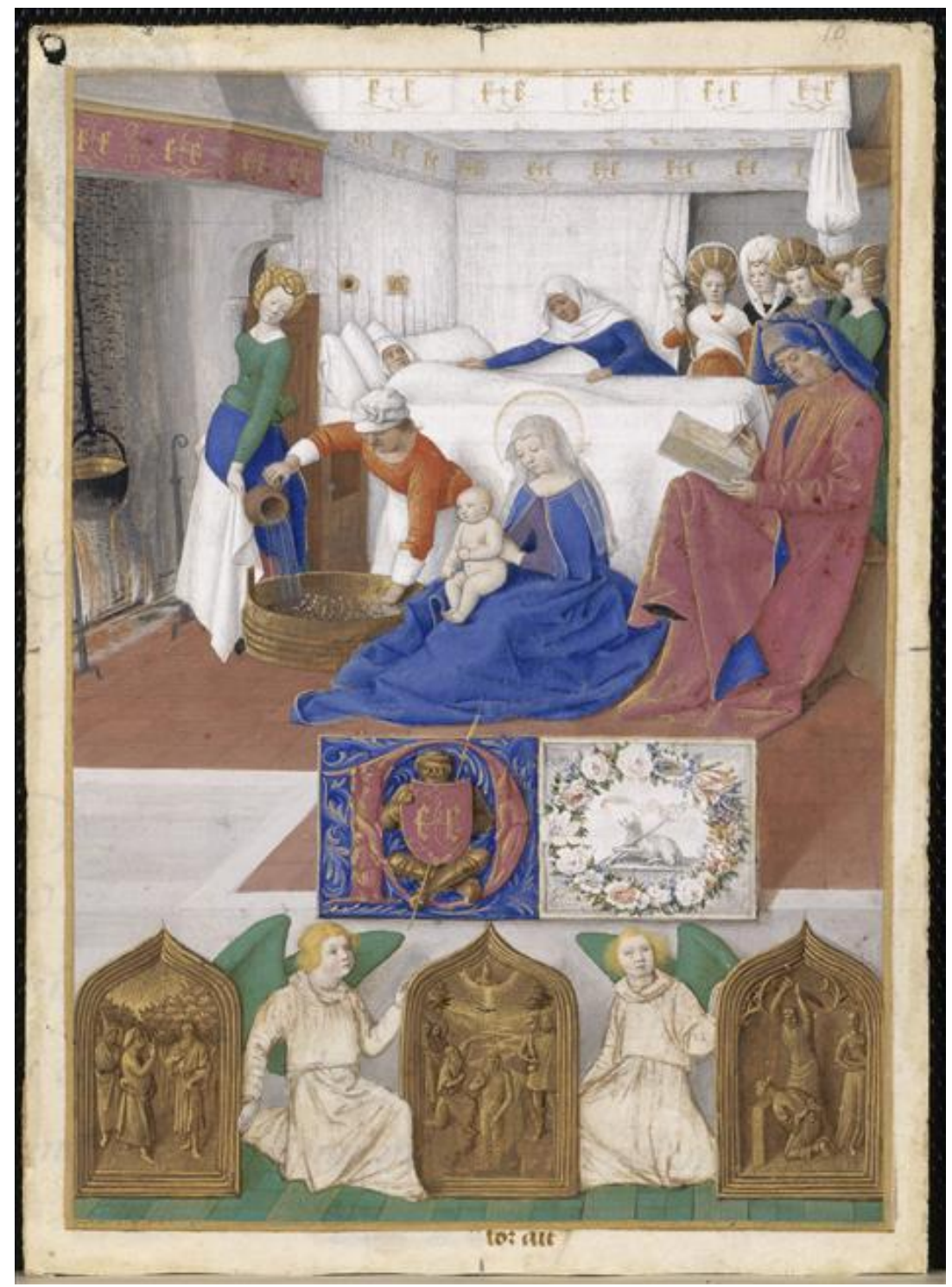

Fig. 2. Ilustración que permite ver las características de un paramento de cama, con sus cortinas. J. Fouquet, Libro de Horas de Étienne Chevalier, 1452-1460. Museo Condé. Chantilly.

Además de las cortinas, componía el paramento o pabellón de la cama el llamado "cielo" o "sobrecielo", que abarcaba toda la anchura y largura del lecho, de forma que cubría, protegía y decoraba la zona superior del mismo. La parte interior del cielo podía realizarse con la misma tela escogida para cubrir la cabecera de la cama, como se ve en el Nacimiento de la Virgen del artista alemán conocido como Maestro de la vida de la Virgen, ya mencionado. Del cielo o sobrecielo pendían las "goteras", una franja o banda ancha que rodeaba el paramento, disimulando y al tiempo decorando la unión entre aquel y las cortinas.

En algunos inventarios se citan paramentos con "mangas", que formaban parte de los ajuares textiles de las llamadas "camas de campo" con una estructura arquitectónica definida, por lo que cabe suponer que serían piezas de 
tela para revestir y ornar las columnas que sostenían la cornisa, posiblemente por la zona interior del paramento. ${ }^{19}$ Es posible que el nombre se adoptara por la semejanza con la forma y función que tiene la manga de una vestidura, tal como ocurrió en el caso del ornamento sagrado llamado también "manga", utilizado para cubrir el armazón, con su vara vertical y aros de madera, que permitía sostener la cruz de las iglesias en las procesiones. En Francia, en las camas del siglo XVII se habla del uso de "guardamalletas" o envolturas que disimulaban estas columnas. ${ }^{20}$ La voz manga pudo ser el antecedente de este último término que no aparece todavía en el Diccionario de Autoridades, aunque sí en léxicos y diccionarios del siglo XIX, en los que se define como una pieza de adorno que pende sobre el cortinaje por la parte superior y permanece fija. ${ }^{21}$

Las cortinas que rodeaban la cama permitieron que los ocupantes de la misma tuvieran una cierta privacidad y protección física, creando un espacio propio dentro de una estancia más amplia, en unos entornos domésticos en los que no había una delimitación clara de las funciones de las habitaciones, ni una separación definida entre las zonas públicas y privadas de la casa. Gracias a estas colgaduras la cama se convertía en un espacio completamente aislado y con entidad propia, que en la Toscana recibía el significativo nombre de camera. ${ }^{22}$ Pero, las cortinas de los paramentos sirvieron también para proteger del frío y crear una cierta sensación de bienestar. Los interiores de las viviendas podían ser gélidos, debido a las deficiencias de los sistemas de cierre y aislamiento de la arquitectura y a los no menos imperfectos métodos calentamiento de las estancias. Los tejidos del lecho completaban la función de aislamiento y caldeamiento que tenían otros textiles utilizados para revestir los muros de las diferentes estancias. Esclarecedora resulta, en este sentido, la petición que en 1617 dirigió Lope de Vega a su protector el duque de Sessa: "Suplico a V. ex", mande que me den para este aposentillo donde me muero de frío, cinco reposteros de lana, que los bolberé a las açémilas pasado el frío; y antes por dicha si me concierto en unos tapizes viejos..."23

$\mathrm{Al}$ cerrar las cortinas, que se fijaban con alfileres para conseguir un mejor ajuste, se lograba aislar el lecho de las corrientes del aire y mantener la temperatura. El calor producido por los cuerpos de los durmientes se conservaba mejor en un reducto protegido y aislado por el paramento y gracias al uso de otros textiles de abrigo que formaban parte de la dotación de la cama. Un medio más eficaz de calentar la cama fue el llamado "escalfador", citado con frecuencia en los inventarios aragoneses de los siglos XV y XVI. Estos escalfadores constaban de un recipiente que podía ser de alambre (cobre), "azofar" (latón), o incluso plata, en el que colocaban las brasas y de un mango de madera para poderlo coger sin quemarse y deslizarlo entre las sábanas. ${ }^{24}$

Sobre la base horizontal de la cama se tendían los colchones y otros elementos textiles. Los antecedentes del colchón estarían en la idea más primitiva de la cama: un simple amontonamiento de paja sobre la que yacer, que después se introdujo en un sencillo saco o bolsa. Las fuentes británicas hablan de otros materiales sobre los que tenderse para dormir: aulagas, algas o vainas de guisantes. Por su parte, Covarrubias señala que al principio, las camas, fueron de 
"yerbas quebrantadas y torcidas". ${ }^{25} \mathrm{El}$ colchón totalmente constituido es definido por el Diccionario de Autoridades como una "invención que para la comodidad, mayor reposo y regalo, hallaron los hombres, para usar de ella en las camas, y acostarse blandamente" que adquiría su forma mediante "dos lienzos, terlices, ù otra tela iguales, proporcionados al tamaño de la cama, entre los quales se mete porcion de lana, pluma ù otra materia". 26

En los siglos XV y XVI los colchones se rellenaban con lana de diferente calidad. Los mejores colchones eran de lana fina y buena, pero también había colchones de borra, un tipo de lana más grosera y de inferior condición. ${ }^{27}$ Parece que los romanos hicieron uso de colchones de pluma, "culcita plumae", un tipo de material que es mencionado también en los escritos de Petrarca. Señala Covarrubias que en Vizcaya y en otros lugares se utilizaban plumones para embutir los colchones, sin embargo en las referencias documentales se menciona exclusivamente el empleo de lana. A finales del siglo XV, en la documentación aragonesa, aparece con cierta frecuencia la voz "plumaço", "plumaça" o "plumazo", que, en opinión de Martín Alonso y Joan Corominas sería un colchón o almohada grande llena de pluma. ${ }^{28}$ Pero, las acotaciones recogidas en los documentos, hacen pensar que el plumazo no sería un colchón de pluma. En varias ocasiones se habla de un plumazo "pleno de pallya" o "con palla", es decir, lleno de paja, característica que ya contempló parcialmente Pottier al referirse a estos plumazos como colchones de pluma o de paja. ${ }^{29}$

Los colchones presentaban "suelos" y "caras" confeccionados con tejidos de diferente índole. Hubo colchones de telas bastas como el crudo y tosco cañamazo, el bocarán, tieso y engomado o el anjeo de lino grueso o de estopa. También se usaron con este propósito tejidos de calidad media y alta, como el lino, el cáñamo, el terliz o la cotonina, y el ruán, un tejido delicado, procedente de la ciudad francesa de Rouen, que podía ser de lino fino y delgado, o de algodón estampado de diversos colores. ${ }^{30}$ La condición de los tejidos empleados para confeccionar la cobertura del colchón marcaba el propio valor de éste. Así, los colchones de ruán fueron propiedad de personas de alta condición, como don Miguel Matías Climent o don Jusepe de Aragón. ${ }^{31}$ Además, las telas usadas en los colchones podían presentar una decoración propia que, con frecuencia, consistía en listas de diferentes colores. Por otro lado, ciertos tejidos empleados para la hechura de colchones, como la cotonina o el terliz, tenían una superficie ornamentada con diseños listados o escaqueados. ${ }^{32}$

El número de colchones variaba de unas camas a otras. Una cama sencilla, como la que usaban los criados de la casa, podía tener un único colchón, mientras que en las llamadas "camas de campo" se usaban tres y, con más frecuencia, cuatro colchones. ${ }^{33}$ En algunos inventarios se mencionan colchones con sus "fijuelas" o "hijuelas" de lana. ${ }^{34}$ La hijuela era un colchoncillo delgado y pequeño con el que se intentaba conseguir un mayor reposo y confort en el lecho. Se colocaba entre los demás, "para que con el peso del cuerpo no haga hoyo la cama y se evite la incomodidad que esto suelo causar". ${ }^{35}$

Junto al colchón se menciona en los inventarios una pieza denominada "marfega" o "márfega", voz que ha sido objeto de distintas interpretaciones. En el 
Diccionario de Autoridades se emparenta esta palabra con el vocablo "marga", que hace referencia a una tela de estopa basta utilizada para hacer sacas de lana y otras cosas de similar naturaleza. Este mismo significado es recogido por Martín Alonso, autor que completa el sentido del término, señalando que en Aragón márfega era un colchón de paja, esparto o hierba sin bastas. En la misma línea Pottier señala que la márfega es una "paillasse, matelas de tissu grossier, en canyamaz et rempli de paille". Por su parte, Corominas recoge distintas variantes desde "marga", a "márrega", "márraga" pasando por "márfaga" y señala que en el aragonés, esta palabra, que procedería del árabe vulgar márfaqa, seguía viva aún hacia 1630 con la acepción de jergón. ${ }^{36}$

En la documentación aragonesa se alude con frecuencia a estas "marfegas" o "márfegas", que estaban rellenas de paja o servían para tener paja37 y se confeccionaban con tejidos bastos y comunes como el cañamazo, y el vitre, una especie de lona que se fabricaba en la ciudad de Vitré, en la Bretaña francesa y que se usaba, entre otras cosas, para hacer toldos o velas de botes. ${ }^{38}$ Por sus características y contexto parece claro que la márfega era una suerte de jergón basto relleno de paja, que se utilizaba en las camas más sencillas y con un número limitado de colchones, uno o dos. No aparecen estas márfegas en camas de campo y camas con paramentos y pabellones, en las que se hacía uso de un mayor número de colchones. ${ }^{39}$ La márfega sería un elemento intermedio entre las tablas de la base de la cama y el colchón, que constituiría un modesto intento de lograr un cierto aislamiento y una pequeña atenuación de la rigidez de las plataforma lígnea del lecho. En la Jacetania y Alto Gállego, todavía pervive este vocablo para denominar un jergón o colchón relleno de paja, hojas de maíz, esparto o hierba. ${ }^{40}$ En realidad, el uso de estos jergones de paja está documentado en otros lugares de Europa. En el caso de Gran Bretaña, ya en 1492 se usaba la paillasse, un jergón de paja "bien mojada y macerada", sin arrugas y de unos treinta centímetros de grosor. Por su parte, en Francia se documenta el uso, a partir de 1250, de un jergón llamado chutrin, una gran bolsa llena de paja o de hojas secas. ${ }^{41}$

Hubo un tipo de colchón denominado "almadraque", "almadrach", "almadrac" o "almadrat". El término almadraque, procedente del hispanoárabe matráh (árabe mátrah) aparece con gran frecuencia en la documentación aragonesa del siglo XV, centuria en la que la palabra colchón, al menos en el caso de Aragón, no se menciona. ${ }^{42}$ La naturaleza exacta de estos almadraques ha sido objeto de cierto debate entre los lingüistas. Definido como cojín, almohada o colchón, Corominas no comparte la idea de que en castellano esta voz no designó un colchón, sino siempre un cojín y cita al respecto la definición dada por Nebrija, además de obras literarias como el Amadis o la norma recogida en las Ordenanzas de Granada de 1515: "que tengan buenas camas por donde duermen...con sus xergones de paja e sobre ellos un colchón o almadraque de lana con sus dos sávanas". ${ }^{43} \mathrm{El}$ análisis de las relaciones documentales confirma la argumentación de Corominas, el almadraque era sin duda un colchón, que podía usarse en las camas, generalmente superponiendo más de uno, ${ }^{44}$ pero que también se tendía sobre bancos, acomodándose a las dimensiones de éstos, o bien se utilizaba en el estrado. ${ }^{45}$ Covarrubias señala que se trataría de un colchón 
basto usado por los criados de la casa "cuando no se desnudan por estar aprestados para lo que se pueda ofrecer" y, si bien es cierto que hay una referencia al uso de estos almadraques en la habitación de los mozos de servicio, ${ }^{46}$ los materiales, color y la decoración de los mismos indica que serían piezas versátiles, de una notable riqueza y fantasía en algunos casos. El relleno de un almadraque podía ser de lana o borra. ${ }^{47}$ En los almadraques se usaron telas de calidad inferior, como el bocarán, o el lienzo, pero también paños de seda bordados con decoraciones vegetales de distinto tipo. ${ }^{48}$ Sobresalen estos almadraques por el uso de diferentes coloraciones, bien cubriendo de forma uniforme la superficie textil o mediante listas y franjas de tonos diferentes y alternos. Sin duda, la decoración más curiosa es la de unos almadraques con "pintas de ffardachina", que podría ser una tela con manchas similares a las que presenta la piel de un lagarto (fardacho en Aragón), sin duda una alternancia cromática poco usual y sorprendente. 49

La cabecera del lecho estaba ocupada por una almohada grande, denominada "cabezal", término con el que se aludía a su posición y también al hecho de que sobre ella se apoyaba la cabeza. También se llamó "travesero", o "travesaño", pues era la almohada que atravesaba toda la anchura de la cama. Este nombre coincide con el francés, idioma en el que se se llamó a esta almohada "traverslit", "travesier", "traversain" o "traversin".50 El cabezal o travesero se rellenaba con pluma y con "flojel" o "flujel", una suerte de plumón o "pelillo que tiene las aves, que aun no llega à pluma". Hubo cabezales o traveseros realizados con tejidos ordinarios y resistentes, de fuerte trama, como el lienzo grueso, el anjeo, o el fustán, pero también se hicieron otros con telas más finas y caras, como el ruán, un lienzo de lino delgado que se fabricaba en la ciudad francesa de este nombre, y especialmente la holanda, tejido de lienzo de lino, de gran finura, y delicado color blanco, llamada así por realizarse en Holanda y otras zonas de las Provincias Unidas. ${ }^{51} \mathrm{El}$ empleo de uno u otro tejido indica el valor diferente de este tipo de almohadas, así como la condición de los lechos en los que se incluían. Así, en el inventario de las ropas de cama del rey Felipe II figuran varios traveseros de holanda cuidadosamente ornados. ${ }^{52}$ Refleja, asimismo, que estas almohadas eran elementos visibles, y como tales una expresión directa del rango. El travesero o cabezal recibió su propia decoración mediante la introducción de listas de color de distintas tonalidades. ${ }^{53}$ Pero los traveseros ricos fueron ornados de forma más sofisticada, con vivos y guarniciones realizados con sedas de colores, labores labradas también en sedas polícromas o decoraciones de red de encaje. En algunos casos se mencionan ejemplos bordados con cadenetas, punto de matiz y plata $u$ oro matizado. Los dos últimos puntos eran de mayor complejidad y riqueza, especialmente el oro matizado, y se reservaban para la representación de motivos vegetales, animales o figurativos. Felipe II poseyó unos cuantos traveseros con botones de oro, labrados también con oro y plata hilados y escarchados, y ornados con labores vegetales hechas con hilo de seda ${ }^{54}$.

Pero en las camas no se utilizaba una única almohada. De hecho, en las relaciones documentales se habla de cabezales o traveseros con sus almohadillas. Una de estas almohadillas recibió una denominación específica, "acerico" o "aciruelo". El término acerico se utilizó en Castilla, mientras que aciruelo, con 
sus variantes "açiruelo", "acircuelo", "azeruelo" fue una voz usual en la documentación aragonesa de los siglos XV y XVI. ${ }^{55}$ El acerico o aciruelo era una almohada pequeña para apoyar la cabeza y el rostro, que podía ponerse sobre el cabezal o travesero de la que era un complemento, y se confeccionaba con los mismos tejidos y decoraciones que éste. ${ }^{56}$ Dicho uso puede verse en numerosas obras de la época, como la miniatura que ilustra Los castigos del rey Sancho IV, del primer tercio del siglo XV, en las que aparecen varias almohadas superpuestas, de la misma forma que se dormía sobre varios colchones. En pinturas como el Nacimiento de la Virgen de Bocaccio Bocaccino (1515) o en las versiones del mismo tema pintadas por Carpaccio hacia 1504-1508 y Jacob Cornelisz van Oostsanen, en 1520, se observa que la colocación de dos o más almohadas permitía tener la cabeza más alta que el cuerpo, incorporarse sobre el lecho en posición semisentada o apoyarse en un codo. Estas posturas serían habituales, habida cuenta de la versatilidad de estas camas, en las que se dormía, pero también se comía o se recibían visitas.

Además de éstas y otras almohadas, se usaban en las camas cojines, si bien no siempre es posible saber la función de unos y otras, pues también se empleaban como complemento de los muebles de asiento, o en el espacio del estrado, por mencionar dos de estos usos. A veces, las fuentes aclaran si estas piezas son cojines o almohadas de cama y de dormir o elementos para sentarse o para colocar sobre una alfombra. Incluso se habla directamente de "almohadas de estrado". ${ }^{57}$ De hecho, la función de asiento fue fundamental en el origen de estas almohadas y cojines, que antes de alcanzar la cama se usaron primero en sillas o bancos. P. Dibie y J. Corominas señalan que la palabra cojín y su equivalente francesa "coussin" proceden del latín vulgar "coxinum", derivado de "cǒxa", "cadera", pues servían para sentarse encima. ${ }^{58}$

En la cama, estas almohadas y cojines se confeccionaban en ocasiones a juego con las colchas o cobertores, como elementos de adorno. A veces, se habla de "almohadas de color", probablemente para diferenciarlas de traveseros y acericos que se realizaban con tejidos blancos. Podían llevar flores en su interior, costumbre que también se ha documentado en la corte del rey Enrique VII de Inglaterra, en cuyas regulaciones domésticas se especificaba que los criados habrían de recoger hierbas aromáticas o raíces, para conseguir buen olor y una mayor sensación de higiene en las batas o sábanas del rey. En Francia, desde la Edad Media, se ponían sobre la colcha o en medio de la ropa blanca almohadillas perfumadas, con aromas de almizcle, ámbar y azafrán o de lavanda y violeta. ${ }^{59}$ Algunos cojines y almohadas alcanzaban una notable riqueza, se confeccionaban con tejidos de gran calidad y se decoraban con labores de bordado de seda y oro o con encajes y borlas en los ángulos. Excepcionales son las almohadas o cojines situados sobre la cama de la escena de La Anunciación realizada por Carlo Crivelli en 1486 y conservada en la National Gallery. Rematadas con borlas en sus esquinas y bordadas con hilo de oro por sus orillos, armonizan con la no menos suntuosa colcha y constituyen un ejemplo del lujo que se alcanzó en algunas de estas piezas. 
Fundamentales en la cama eran los textiles que servían para la cubrición y el abrigo y que se tendían por encima de los colchones. En primer lugar las sábanas, que introducidas por los musulmanes en España, se difundieron paulatinamente por Europa hasta alcanzar la totalidad del continente a finales de la Edad Media. ${ }^{60}$ La sábana supuso un refinamiento en el ajuar de la cama, por un lado evitaba el contacto de la piel con los tejidos de colchones y cubiertas, por lo general de más cuerpo y aspereza. Por otro, permitía la introducción de cierta higiene, pues a diferencia de otras telas, era posible lavarlas e incluso perfumarlas. El término sábana procede de latín "sabăna", plural de "sabănum", toalla de baño. Fue una palabra que tuvo un significado más amplio que el actual: hay referencias medievales en las que se habla de sábanas para cubrir el altar o los muros y en la documentación del siglo XVI se mencionan "sábanas de aparador", que servían para vestir este mueble en el que se exponía la vajilla.61 Una palabra muy usada en el siglo XV y todavía en el XVI para referirse a lo que hoy denominamos sábana fue "linzuelo" o "lenzuelo". También en Francia, al menos hasta el siglo XII, la sábana se llamó "lincel" "linceul", del latín "linteolum", diminutivo de "linteum", tela de lino, en alusión a uno de los tejidos más usados en la confección de sábanas. Asimismo, en italiano se usó el vocablo "lenzuelo". De hecho, todavía existían formas derivadas de este vocablo en el siglo XIX, en zonas del Macizo Central, el Jura y Los Alpes Septentrionales y en Aragón, en la Jacetanía y Alto Gállego. ${ }^{62}$

Los materiales usados para confeccionar sábanas o linzuelos fueron diversos. Una materia muy utilizada fue el lino, pero también hubo sábanas hechas con telas toscas y sencillas, como la estopa, el anjeo, el cañamazo y el lienzo. Existieron sábanas y linzuelos de brin, que era una tela basta de lino o cáñamo. Otras sábanas se confeccionaron con tejidos de mayor valor, como el naval, de fino tisaje, que se importaba desde Francia o el ruán y la holanda, tela que se reservó para la confección de las mejores sábanas. Incluso hubo sábanas de seda. ${ }^{63}$ La decoración más frecuente de estas piezas fue el encaje. Se mencionan en la documentación aragonesa labores de randas o randadas, una suerte de guarnición unida al tejido de base, que se realizaba según procedimientos técnicos distintos. ${ }^{64}$ Estas randas podían presentar hilos de color, en contraste con la superficie blanca de las sábanas. De hecho, a diferencia de lo que ocurre a partir de mediados del siglo XIX, cuando el color blanco se impone en la lencería, en los siglos XV y XVI las sábanas podían tener detalles ornamentales en alguna gama cromática, o incluso ser de colores diferentes. ${ }^{65}$

Una de las piezas textiles de la cama que da lugar a mayores problemas a la hora de identificar su función y carácter es la llamada "cocedra", "colcedra" o "coceda". Considerada en el Diccionario de Autoridades como un colchón de plumas, cuyo nombre derivaría del latín "culcitra", estaba rellena de pluma o de flujel. Sin embargo, no parece del todo claro que se tratase de un colchón, ya que en el mismo Diccionario se cita un fragmento de las Epistolas familiares de Antonio de Guevara en el que se dice textualmente: "Y en la cama tengan cocédra de pluma para tener mas calor". ${ }^{66}$ Pudo ser, por lo tanto, una especie de bolsa rellena de pluma, como los edredones actuales, que servía como ropa de abrigo. De hecho, en algunos inventarios se habla de la existencia de colchas llenas de 
pluma. ${ }^{67}$ Sin embargo, la cuestión no está nada clara, pues las referencias resultan demasiado parcas. La colcedra o cocedra podría ser la "coltrice", rellena de plumas finas, mencionada por Raffaella Sarti, que en la Edad Moderna se ponía encima de los colchones y sobre la que se tendían las sábanas, pero tambiénesta autora habla de colchas rellenas de plumas y de colchas enguatadas denominadas "coltrone". ${ }^{68}$ La descripción de una cocedra, que perteneció a la reina Juana, con sus caireles, o guarniciones a modo de flecos, sus borlas, cordones y botones alrededor, hace pensar más en un tipo de colcha, visible exteriormente, que en un colchón que se colocaba bajo de las sábanas. ${ }^{69}$ Por otro lado, la frontera entre colchones y colchados rellenos es muy difusa, como se ve en los ajuares de camino de época moderna, en los que se daba una combinación de la "coltrice" y "coltrone", a las que alude Sarti, que cabe relacionar con otra pareja de mullidos de camino compuesta por "trasportin" y "cocera" (colcedra y banova), incluidos entre los bienes de Martín Carrillo, tras su periplo por Italia, antes de convertirse en el abad de Montearagón. ${ }^{70}$

Complicado resulta, asimismo, desentrañar la naturaleza de una prenda denominada "cortapeu" o "cortapisa". Tradicionalmente, se ha entendido que una cortapisa era una guarnición añadida a una superficie textil, para crear así un efecto de contraste. Sin embargo en la documentación aragonesa aparece en un inventario de 1362 "un almadrach con listas cardenas e blancas...en el qual havia una cortapeu cardena de messcla con penya de corderos, blanca”, descripción que parece hacer referencia a un tipo de cubierta confeccionada con lana. Asimismo, en un inventario de los Reales Alcázares de Segovia, realizado en 1503, figura una "cortapisa de lienço tonocí con unas flocaduras blancas". ${ }^{71}$ Corominas señala que la voz cortapisa con su variante cortapeu, que él considera un cruce entre el catalán cortapisa y un sinónimo suyo en este idioma "entornpeu", compuesto por "entorn", alrededor y "peu", pie, sería primitivamente una "colcha basteada para abrigo de la cama". Es posible que cortapisa, se refiriera primero a la colcha, y después a una guarnición de material diferente aplicada a la misma, y que esta segunda acepción se extendiera para designar las guarniciones parecidas que adornaban trajes y otras obras. Así, en otro inventario de 1511 se habla de un delantecama con una cortapisa de randas blancas, que en este caso hace referencia sin duda a una decoración de encaje aplicada a la superficie de la pieza. En los lechos franceses se utilizó la llamada "courtepointe", una colcha guateada y pespunteada. "Courte", sería una forma antigua y alterada de "coute", colchón de pluma y "pointe" es el participio pasado de "poindre", en el sentido de punzar y pinchar", en alusión a las bastas que caracterizan la courtepointe. Fue esta pieza de abrigo documentada en las camas de Francia la que recibiría en España el apelativo de cortapeu, en su variante aragonesa y catalana, y cortapisa, en Castilla. ${ }^{72}$

Otros elementos de abrigo eran las llamadas "licheras" y las mantas. La lichera, también llamada a veces "litera" era en realidad un tipo de manta que recibió esta denominación específica, al menos en Aragón, aunque no es posible saber si hubo alguna característica propia que justificase esta distinción. En numerosas ocasiones se habla de licheras "cardadas", es decir que serían de lana peinada y desenredada con el utensilio llamado carda, para conseguir un 
producto de mejor acabado y fácil de trabajar, aunque también las hubo de pelo de cabra, de algodón, de raz o de raso, por ejemplo. En algunos inventarios se habla de "mantas frazadas" o simplemente de "frazadas", que eran unas mantas de pelo. Mantas y licheras presentaban coloraciones distintas. Las había blancas, pero también de otras tonalidades y muchas mostraban una decoración de listas, también de distinto cromatismo. Estas listas se extendían a lo largo de la superficie de la pieza, o bien se circunscribían al orillo de la misma y podían presentar combinaciones de distintos colores, pero siempre buscando el contraste con la base textil. En ocasiones, la decoración aplicada era más sofisticada, con vuelos y flecos. A veces, hay referencias a la procedencia de estas piezas. Así, se habla de mantas de Castilla, de Ejea, o adquiridas en Valencia, por ejemplo. Y también, se mencionan mantas de "marca mayor", alusión que, como indica el Diccionario de Autoridades especifica una calidad superior, es decir, ${ }^{73}$ "que alguna cosa es excessiva en su línea, y passa y sobrepuja a lo justo y razonable".

Por encima de sábanas y mantas se tendían distintos tipos de colchas o cobertores. En Aragón se menciona una cubierta de cama denominada "banoba", o "vanova", voz específica aragonesa, documentanda ya en el siglo XIV con numerosas variantes, si bien también aparece en catalán y occitano de forma temprana y con notable arraigo en el tiempo. Se ha definido como un tipo de cubierta delicada, que tendría más una función de adorno de la superficie de la cama, que de abrigo. ${ }^{74}$ Para elaborar estas vanovas se usaron con frecuencia tejidos de algódón de distinto tipo, más gruesos y tiesos como el naval, estampados como el cotón o con labores tejidas sobre su superficie, creando un efecto de realce, como la cotonia o cotonina. Pero también se utilizaron tejidos importados de lino fino, como la holanda, el ruán o el cambray, así como telas de seda, entre las que cabe citar el cendal, aunque este tejido podía ser de lino o seda y destacaba por su carácter sutil, ligero y transparente. Una de las características más notables de estas vanovas fue su ornamentación, con variantes distintas: lazos, puntas, rosas, listas de hilo de seda, formas vegetales y pintadas, que se desplegaban por la superficie para enriquecerlas. ${ }^{75}$

Pero en los inventarios aragoneses también se utiliza las denominaciones genéricas de colcha y cobertor y sobrecama que aparecen, asimismo, en la documentación castellana. En el Diccionario de Autoridades se explica que las colchas se hacían con dos telas "embutido entre ellas algodón ù otra materia delicada, y pespuntada con varias labóres", sin embargo este sentido se amplió para aludir en general a una cubierta de cama, aunque se elaborara con una sola tela. Carmen Abad, al estudiar los espacios domésticos en la Zaragoza del siglo XVIII, señala que cuando los cubrecamas son "colchados", es decir entretelados y con pespuntes que distribuyen decorativamente el material de relleno, es cuando se denominan colchas o vanovas. ${ }^{76}$ Durante los siglos XV y XVI resulta muy difícil precisar si hubo diferencias a la hora de usar los términos vanova, colcha, cobertor o sobrecama, pues las descripciones documentales son demasiado someras. Es posible que se usaran estas denominaciones indistintamente, una vez que voces como colcha o vanova, desde un significado inicial más específico, se extendiesen y adquirieran una semántica más general e imprecisa. 


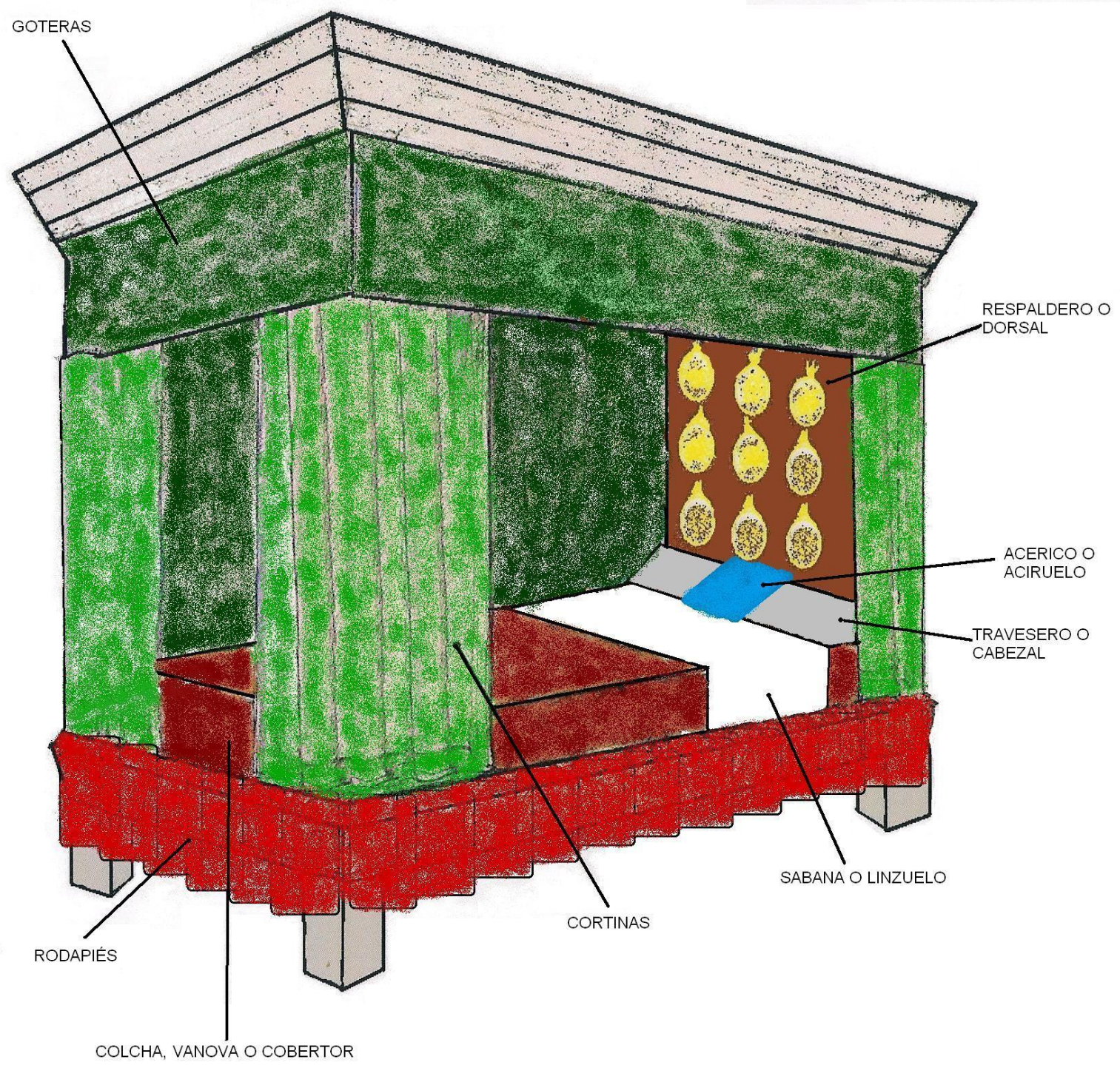

Fig. 3. Esquema de los elementos textiles de la cama. Dibujo Javier Veras Sanz

Colchas, cobertores y sobrecamas se confeccionaron con tejidos distintos como la holanda, la cotonina, el ruán, o con telas de seda como el terciopelo, el tafetán, el raso o el rico brocado y destacaron por la decoración de su superficie con labores distintas. El tipo de material utilizado, así como la ornamentación en ellos desplegada marcó el valor de estos cobertores y colchas, algunos realmente suntuosos. En los inventarios reales es posible encontrar los ejemplos más destacados de estas ropas de cama y calibrar el nivel de refinamiento alcanzado en unas obras que reflejaban el lujo de las camas de esta época. Los hilos de seda y oro se utilizaron para el tisaje de estas obras y para su ornato, con unos trabajos de bordado en los que abunda la decoración floral y vegetal: rosas, lazos, flores de lis, follaje, racimos de uva, alcachofas, decoraciones de grutesco o 
estrellas, e incluso motivos heráldicos. Todo un variado repertorio en el que se buscaba la variedad, la luz, el reflejo de los hilos metálicos y el contraste cromático, cualidades con las que se media su riqueza y belleza. ${ }^{77}$

En la zona superior de la cama se colocaban otros elementos: "antecamas" o "delantecamas" y "rodapiés". El delantecama se relacionaba estrechamente con la colcha, de hecho, en un inventario del alcázar de Segovia de 1503, se habla de colchas con "antecamas" y delanteras de cama. El delantecama se usó para decorar la cubierta del lecho y para evitar que se vieran las patas de la cama. El rodapiés era un paño corrido que se colocaba alrededor de las camas y de otros muebles. Su función era también ocultar las patas del mobiliario, así como proteger de los roces y suciedad la parte inferior de los mismos. La decoración y la calidad de las materias textiles fue una característica general de rodapiés y delantecamas en los lechos de importancia. Ornados con randas y franjas, con decoraciones figurativas, o confeccionados aprovechando otras piezas textiles, algunos ejemplos fueron especialmente lujosos, como los que figuran en el inventario mencionado más arriba, bordados con motivos heráldicos y vegetales en oro y seda. ${ }^{78}$

Finalmente, hay que subrayar el hecho de que muchos de estos elementos externos de la cama, cobertores, sobrecamas, colchas, delantecamas o rodapiés, se realizaban a juego con paramentos y cortinas. Con frecuencia, hubo identidad en los materiales, color o motivos del diseño, pero en otros casos se buscó el contraste cromático. La variedad de materiales y temas ornamentales de estos paramentos o pabellones, así como sus combinaciones en relación con los demás elementos del lecho fue tal, que exigiría un desarrollo monográfico que en esta aproximación al ajuar textil de la cama no es posible abordar con el debido detalle.

\section{Conclusiones}

El estudio de los elementos textiles asociados a la cama en las postrimerías del siglo XV y en la centuria siguiente, revela la enorme variedad de estas piezas y su riqueza material y decorativa. El análisis de las fuentes y la búsqueda de los términos documentales es fundamental para reconstruir su carácter; para conocer una parte del arte textil de la Edad Moderna apenas examinado hasta la fecha y, en definitiva, para reconstruir la función de estas obras textiles en relación con la vivienda, el mobiliario o las formas de vida de la época. 


\title{
NOTAS
}

\begin{abstract}
${ }^{1}$ Esta investigación se ha realizado en el marco de los proyectos de investigación: "El acabado en la arquitectura: los revestimientos cromáticos y otros sistemas decorativos asociados. De la Edad Media a las intervenciones de restauración contemporáneas" (I+D+I. Micinn). Investigadora Principal Carmen Gómez Urdáñez y "El significado de los programas artísticos y musicales en la Península Ibérica durante las Edades Media y Moderna". Investigadora principal: Carmen Morte García. Entidad Financiadora: Gobierno de Aragón. Fondo Europeo de Desarrollo Regional.
\end{abstract}

Por otro lado, deseo expresar mi agradecimiento al profesor René Payo Hernanz por haberme permitido usar su fotografía de la escena de la Anunciación pintada por Juan de Sedano en el armario de las reliquias de la Catedral de Burgos.

${ }^{2}$ El desarrollo de un régimen de vida nómada, en el que el rey y los nobles se desplazaban constantemente para controlar sus tierras, hizo que no resultara funcional trasladar estos armazones, a la sazón muy sencillos, pero sí las ricas telas que los cubrían y que podían volver a montarse sobre una estructura similar en cada residencia.

${ }^{3}$ Pascal Dibie señala que en Francia el papel del textil, lejos de disminuir en el siglo XVII, aumenta cada vez más. En esta centuria se acentuará el lujo y el exotismo, lo que condujo al abandono de las columnas y las cabeceras diseñadas por mueblistas tan relevantes como Ducerceu o Sambin, en favor de numerosas piezas de tela ricamente trabajadas. DIBIE, Pascal, Historia de la alcoba. El dormitorio y la gran aventura del reposo a lo largo del tiempo y las diferentes culturas, Barcelona, Gedisa Editorial, 1989, pp. 104-105. La importancia del tejido tampoco decreció en el siglo XVIII. Carmen Abad observa, al estudiar la casa zaragozana de esta centuria, que se sigue poniendo el acento en el aparejo textil, que marca la tipología y el valor del lecho. ABADZARDOYA, Carmen, La casa y los objetos. Espacio doméstico y cultura material en la Zaragoza de la primera mitad del XVIII, Zaragoza, Delegación del Gobierno en Aragón, 2005, pp. 99-100.

${ }^{4}$ En el Diccionario de Autoridades se recoge esta acepción de la voz cama: "la colgadura de ella, compuesta de cortinas, cenéfa y cielo". Diccionario de Autoridades, (edición facsímil), Madrid, Editorial, Gredos, 1973, Tomo II, A-C, Letra C, pp. 82-83. También Martín Alonso incluye en su Enciclopedia del Idioma, el mismo significado: "Colgadura de lecho compuesta de cielo, cenefas, cortinas y cubierta correspondiente". ALONSO, Martín, Enciclopedia del idioma. Diccionario Histórico y Moderno de la lengua española (siglos XII al XX). Etimológico, tecnológico, Regional e Hispanoamericano, Madrid, Editorial Aguilar, 1958, Tomo I, letras, A$\mathrm{CH}$, p. 870. Lawrence Wright recoge un inventario realizado en Devon en el año 1400, en el que al hablar de la camas se las describe aludiendo exclusivamente a sus componentes textiles. WRIGHT, Lawrence, Caliente y confortable. Historia de la cama, Barcelona, Editorial Noguer, 1964, p. 69. En la documentación española se observa la misma tónica. Sirva como ejemplo el inventario de los bienes de Miguel Matías Climent, realizado en 1596, en el que se habla de una "cama de terçiopelo verde y damasco con franjas y alamares de oro y la madera lisa de nogal" y otra "cama de damasco naranjado, sin oro, con todo su adreço..." de la que ni siquiera se menciona el tipo de estructura de madera. MORTE GARCÍA, Carmen, ÁLVAREZ CLAVIJO, María Teresa, MATEOS GIL, Ana Jesús, "La colección de pinturas, tapices, dibujos, estampas y esculturas de Miguel Climent Gurrea, protonotario del Consejo Supremo de Aragón y otros inventarios del siglo XVI", Boletín del Museo e Instituto "Camón Aznar", volumen LXV, Zaragoza,1996, pp. 134-135. María Paz Aguiló, también sostiene que la principal característica de las camas en esta época se centra en la riqueza y abundancia de las telas. AGUILÓ ALONSO, María Paz, El mueble en España. Siglos XVI-XVII, Madrid, Consejo Superior de Investigaciones Científicas. Ediciones Antiquaria, 1993, p. 144.

${ }^{5}$ SÁNCHEZ CANTÓN, Francisco Javier, Archivo Documental Español publicado por la Real Academia de Historia. Inventarios Reales. Bienes Muebles que pertenecieron a Felipe II, Tomo X, Madrid, Real Academia de la Historia, MCMLVI-MCMLIX, vol. I, p. 218. El valor de estas camas puede establecerse en comparación con otros bienes. Así, una cama de damasco naranja, con todo su aparejo, caídas de terciopelo verde y franjas de seda, con un tapete a juego, que perteneció a don Miguel Matías Climent, se vendió por 136 libras, cantidad no muy alejada de las 178 libras y 12 sueldos en los que se valoraron dos vasos imperiales de plata con su tapa, dos tazas imperiales, un salero dorado, y una pieza para contener agua que figuran en la misma relación. Una precio muy superior que el obtenido por la pintura, pues cuatro retratos "de las tres Reynas y del Prinçipe Don Carlos, guarneçidos con marcos de madera" se vendieron por 43 libras y uno del rey Felipe II por 11 libras: MORTE GARCÍA, Carmen, ÁLVAREZ CLAVIJO, María Teresa, MATEOS GIL, Ana Jesús, op. cit., pp. 153-156.

${ }^{6}$ SARTI, Raffaella, Vida en familia. Casa, comida y vestido en la Europa moderna, Barcelona, Editorial Crítica, 2003, p. 157.

${ }^{7}$ Ibidem, p. 66. En las capitulaciones matrimoniales firmadas entre el labrador Miguel Rey y Martina de Realte, ésta se comprometía a aportar al matrimonio "una cama de ropa en la qual aya dos bancos, cinco tablas de fusta, 
una marfega, un colchon de lana, dos pares de sabanas de lino, una manta cardada nueba, un par de almohadas con sus enfundias y un delantecama randado". Archivo Histórico de Protocolos de Zaragoza, en adelante [A.H.P.Z], Juan Campi, 1546, f. 283r). Mucho más ricas eran las camas que doña Jerónima de Ariño, hija de don Manuel de Ariño y doña Blanca de Gurrea, recibió de su madre, tal como consta en el testamento de ésta última. Eran dos camas de campo que formaban parte de los bienes, joyas y dinero que ésta se había comprometido a entregarle cuando contrajo matrimonio con el infanzón Miguel Cósida. La primera de ellas constaba de "tres colchones, un paramento de grana con goteras de terciopelo verde y delante cama", valorada en 660 sueldos. La segunda tenía "pilares jaspeados y las mancanas doradas con dos cortinas y sobrecielo de zarzan y dos cortinas de tafetan colorado, tres mangas y goteras de terciopelo carmesi", estimada en 1.320 sueldos.

${ }^{8}$ Así es definido en la octava edición del Diccionario de la Lengua Castellana. Martín Alonso, recoge en su Enciclopedia del Idioma el término "ciegayernos" y lo define de forma similar. ALONSO, Martín, op. cit., Tomo I, letras, A-CH, p. 1057. Por su parte, Pottier, equipara esta palabra con el sustantivo "esombraduenyas". POTTIER, Bernard, "Etude lexicologique sur des inventaires aragonais", Vox Romanica, 10, Berna, 1948-1949, pp. 218. Variantes de este vocablo sería la voz "espantavillanos" que alude también a un objeto brillante y de poco valor, cuyo objetivo sería engañar a la gente sencilla. Entre los bienes del jurista Galcerán Ferrer había, en 1497, un lecho encajado con "unos engaya yernos alraedor": SERRANO Y SANZ, Manuel, "Inventarios aragoneses los siglos XIV y XV", Boletín de la Real Academia española, Año II, Tomo II, Madrid, Febrero 1915, Cuaderno VI, p. 90.

${ }^{9}$ Las camas de este período son en su mayoría desmontables y suelen figurar sin armar, con todo el aparejo necesario para su construcción guardado en arcas o baúles. Entre los objetos propiedad de don Alonso de Aragón, abad de Montearagón, había una "cama de campo de nogal con sus pilares torneados y siete tablas de pino y sus varas de fierro y todo lo necessario para pararla dentro de dos bahules de sayal guarnicidos de cuero". A.H.P.Z., Miguel Español, 1552, folios sin numerar. Y la suntuosa cama de campo propiedad del protonotario Miguel Climente Gurrea, aparece en el inventario de sus bienes con su rica estructura de madera totalmente acoplada, pero desnuda, mientras que el ajuar textil que la acompaña se guarda en un arca de pino cerrada: A.H.P.Z., Cristóbal Navarro, 1562, f. 562r. Este inventario fue transcrito en gran parte por MORTE GARCÍA, Carmen, ÁlVAREZ CLAVIJO, María Teresa, MATEOS GIL, Ana Jesús, op. cit., pp. 148-152. Diccionario de Autoridades, op. cit., Tomo II, A-C, Letra C, su voz, pp. 82-83. Algunas de estas camas tenían ya pilares visibles, que sostenían cornisas horizontales, con manzanas y otros motivos en su remate. GÓMEZ URDÁÑEZ, Carmen, Arquitectura civil en Zaragoza en el siglo XVI, Zaragoza, Ayuntamiento, 1987, Tomo I, p. 146. Estas manzanas podían estar adornadas también con fibras textiles a juego con los demás tejidos que constituían la dotación del lecho. Entre los bienes del rey Felipe II había una cama de velo blanco de la India, con "quatro manzanillas cubiertas de torzales de seda blanca”. SÁNCHEZ CANTÓN, Francisco Javier, op. cit., p. 220. También María Paz Aguiló habla de que estas manzanas podían forrarse con pasamanería de oro. AGUILÓ ALONSO, María Paz, op. cit., p. 145.

${ }^{10}$ En el Diccionario de Autoridades, op. cit., O-Z, Tomo V, p. 121, se define paramento como adorno o atavío con que se cubre alguna cosa. Entre los bienes del jurista Galcerán Ferrer figuraban en 1497 varios paramentos de cama: SERRANO y SANZ, Manuel, op. cit., Año II, Tomo II, febrero 1915, Cuaderno VI, pp. 87-92 y a lo largo del siglo XVI la voz paramento sigue apareciendo en las fuentes con gran frecuencia: A.H.P.Z., Juan Abad, 1504-1505, ff. 321v y 328r; Miguel Villanueva, 1504, f. 275r; Miguel de Villanueva, 1505, f. 349v; Juan de Arruego, 1523, ff. 267 r y siguientes sin numerar; Agustín Casales, 1566, f. 346v; Juan Escartín, 1596, f. 65r.

11 A.H.P.Z., Luis Sora, 1527, f. 247v; Martín de Blancas, 1534, ff. 141v, 143r t 175r; Pedro Martínez de Insausti, 1546, f. 654r; Pedro López, 1548, f. 587r; Miguel Español, 1552, folios sin numerar; Cristóbal Navarro, 1562, f. 573r; Jerónimo Andrés mayor, 1585, ff. 419v y 521r y Pablo Villanueva, 1599, folios sin numerar después del 770r. Entre los bienes que se encontraban en el tesoro del Alcázar de Segovia había en 1503 varios pabellones de cama, aunque también se menciona un paramento: FERRANDIS, José (Transcripción y prólogo), Datos documentales para la Historia del Artes Español. Tomo III. Inventarios Reales (Juan II a Juana La Loca), Madrid, 1943, pp. 107-109. Por su parte, Felipe II poseía un pabellón de tafetán blanco pintado: SÁNCHEZ CANTÓN, Francisco Javier, op. cit., p. 219.

12 COROMINAS, Joan, (con la colaboración de PASCUAL, José A.), Diccionario crítico etimológico castellano e hispánico, Madrid, editorial Gredos, 1980, Tomo IV, ME-RE, p. 329; COVARRUBIAS, Sebastián, Tesoro de la lengua castellana o española, Madrid, Editorial Castalia, 1994, p. 794; Diccionario de Autoridades, op. cit., Tomo V, O-Z, p. 69.

${ }^{13}$ Véase HERRERO CARRETERO, Concha NELlO FORTI, Grazzini (textos), Los amores de Mercurio y Herse. Una tapicería rica de Willem de Pannemaker, Madrid, Museo Nacional del Prado, 2010, p. 64. 
${ }^{14}$ A.H.P.Z., Miguel Español, 1552, folios sin numerar y SÁNCHEZ CANTÓN, Francisco Javier, op, cit., p. 219.

${ }^{15}$ ALONSO, Martín, op. cit., Tomo I, letras, A-CH, p. 919

${ }^{16}$ María Paz Aguiló sí emplea el término pabellón para referirse a una especie de tejadillo, con una elevación en el centro, que se diferenciaría de las cubiertas textiles en disposición horizontal. AGUILÓ ALONSO, María Paz, op. cit., p. 146.

${ }^{17}$ José Ferrandis recoge los términos corrediza, para denominar a las "cortinas", así como los de "costanera" o "costañera" y "caveçera". FERRANDIS, José, op. cit., pp. 26 y 330-332.

${ }^{18}$ A.H.P.Z, Francisco Sebastián, 1556, ff 141r y siguientes sin numerar (referenciado por GÓMEZ URDÁÑEZ, Carmen, op. cit., p. 142); WRIGHT, Lawrence, op. cit. p. 68.

19 "Mas un paramento de girasol con su sobrecama de campo que son quatro cortinas con dos mangas y el cielo con goteras de terciopelo morado...”: A.H.P.Z., Francisco Sebastián, 1556, f, 141r y siguientes sin numerar (referenciado por GÓMEZ URDÁÑ̃EZ, Carmen, op. cit., p. 142). Paramentos con mangas se citan también en el inventario de los bienes de Miguel Climent Gurrea: "Item un paramento de cama de campo de paño amarillo con sobrecielo y cinco cortinas con sus goteras, mangas y delante cama con franjas de esfiladiz amarillo": A.H.P.Z., Cristóbal Navarro, 1562, ff. 562r, 571r, 573r. Este último inventario fue transcrito en parte por MORTE GARCÍA, Carmen, ÁLVAREZ CLAVIJO, María Teresa, MATEOS GIL, Ana Jesús, op. cit., pp. 148-152. Otros ejemplos en A.H.P.Z., Martín de Blancas, 1534, f. 141v, documento en el que aparecen varios paramentos de camas de campo con sus mangas; A.H.P.Z. Jimeno Sanz del Villar, 1535, f. 562r. Asimismo, aparece el término manga en una colgadura de cama de tafetán carmesí que perteneció a Felipe II: SÁNCHEZ CANTÓN, Francisco Javier, op. cit., p. 219.

${ }^{20}$ DIBIE, Pascal, op. cit., p. 105.

${ }^{21}$ Así se define, por ejemplo en el Diccionario General de la Lengua Castellana, Madrid, Casa Editorial Saturnino Calleja Fernández, posterior a 1876, p. 1059.

${ }^{22}$ SARTI, Raffaella, op. cit., p. 158.

${ }^{23}$ Recogido en REIG, Rafael, Señales de humo. Manual de literatura para caníbales, Barcelona, Tusquets Editores, 2016, p. 341.

${ }^{24} \mathrm{El}$ término escalfador deriva de "escalfar", que a su vez deriva de "calfar", del latín vulgar "calfara", latín "calefatare" compuesto de "calere", estar caliente y facere. En LAGUNA CAMPOS, José, "Estudio léxico de un inventario oscense de 1565", Archivo de Filología Aragonesa, vol. 46-47, 1991, p. 53. Escalfadores aparecen en A.H.P.Z., Jerónimo Andrés mayor, 1585, ff. 522v-523v, 639v. En el testamento de doña Leonor Zaporta se cita una "escalfadorçico de plata": A.H.P.Z., Jerónimo Andrés, menor, 1590, f. 1189v. Estos calentadores de cama se siguieron usando hasta el siglo XX. Carmen Abad-Zardoya los registra en las casas aragonesas del siglo XVIII, conviviendo con otros objetos que se utilizaban también para calentar la cama, como las "tumbillas": ABADZARDOYA, Carmen, op. cit., p. 153.

${ }^{25}$ WRIGHT, Lawrence, op. cit., pp. 73-74. COVARRUBIAS, Sebastián, op. cit., pp. 331-332.

${ }^{26}$ Diccionario de Autoridades, op. cit., Tomo II, A-C, Letra C, su voz, p. 407.

${ }^{27}$ A.H.P.Z., Juan de Arruego, 1511, folios sin numerar después del 386r (referenciado por GÓMEZ URDÁÑEZ, Carmen, op. cit., p. 146); Juan Abad, 1504-1505, f. 325r y Miguel Villanueva, 1505, f. 422v.

${ }^{28}$ ALONSO, Martín, Enciclopedia del idioma, op. cit., Tomo III, letras N-Z, p. 3324 y COROMINAS, Joan., op. cit, Tomo IV, ME-RE, p. 383.

${ }^{29}$ SERRANO y SANZ, Manuel, op. cit., Año II, Tomo II, Octubre 1915, Cuaderno IX, p. 551 y Año IV, Tomo IV, Junio 1917, Cuaderno XVIII, pp. 344-345. POTTIER, Bernard, op. cit, p.193.

${ }^{30}$ Las características de todos estos tejidos pueden consultarse en DÁVILA CORONA, Rosa Ma , DURÁN PUJOL, Monserrat y GARCÍA FERNÁNDEZ, Máximo, Diccionario Histórico de telas y tejidos. CastellanoCatalán, Salamanca, Junta de Castilla y León, 2004. Colchones manufacturados con estos tejidos son mencionados en A.H.P.Z., Juan Abad, 1504-1505, f. 322v; Miguel Villanueva, 1505, f. 422v y 1510, f. 395r; Luis Sora, 1526, f. 93v; Jimeno Sanz del Villar, ff. 560v, 565r y v; 568r y 569v; Jerónimo Andrés, mayor, 1585, f. 511v.

${ }^{31}$ A.H.P.Z., Juan Escartín, 1596, f. 68r; Pablo Villanueva, 1599, folios sin numerar a partir del 770r (estos dos últimos inventarios transcritos en parte por MORTE GARCÍA, Carmen, ÁLVAREZ CLAVIJO, María Teresa, MATEOS GIL, Ana Jesús, op. cit., pp. 152-161). 
${ }^{32}$ A.H.P.Z., Ximeno Gil, 1513, f. 26r; Juan de Arruego 1523, folios sin numerar después del 408v (referenciado por GÓMEZ URDÁÑEZ, Carmen, op. cit., p. 141); FERRANDIS, José, op. cit., p. 108.

${ }^{33}$ A.H.P.Z., Cristóbal Navarro, 1562, ff. 562r, 579ry v, 585r (inventario transcripto en parte por MORTE GARCÍA, Carmen, ÁLVAREZ CLAVIJO, María Teresa, MATEOS GIL, Ana Jesús, op. cit., pp. 152-159); Francisco Sebastián, 1556, folios sin mumerar después de 141 r (referenciado por GÓMEZ URDÁÑEZ, Carmen, op. cit., p. 139); Agustín Casales, 1566, f. 346v;

${ }^{34}$ A.H.P.Z., Juan de Arruego, 1523, folios sin numerar después del 267r; Luis Sora, 1526, f. 92v; Cristóbal Navarro, 1562, f. 587r; ARCHIVO CAPITULAR DE LA SEO DE ZARAGOZA, [A.C.S.Z,] Cuadernillo sin foliar, Privilegios, Letra L, $\mathrm{n}^{\circ} 23(23-2)$

${ }^{35}$ Diccionario de Autoridades, op. cit., Tomo III, Letra H, su voz, p. 157.

${ }^{36}$ Diccionario de Autoridades, Tomo IV, D-Ñ, su voz, p. 498; ALONSO, M, Enciclopedia del idioma, Tomo II, letras, D-M, p. 2718; POTTIER, Bernard, op. cit., p. 175 y COROMINAS, Joan, op. cit., G-MA, Tomo III, p. 851. Corominas es el autor que se extiende más en la búsqueda del origen etimológico de esta palabra. Señala que Pedro de Alcalá en su obra Arte para ligeramente saber la lengua aráviga y Vocabulista arávigo en Lengua castellana, traduce la voz márfaqa como un "cabeçal o almohada de cabeça" y "cabecera de cama" y que de ahí derivaría el cambio semántico de "cojín", "almohada", "jergón" y más tarde "jerga para hacer jergones". Esta voz experimentaría una evolución fonética hasta llegar a la denominación marga, que se usó para designar el tipo de tejido grosero utilizado para realizar jergones y también las sacas a las que se aludía en el Diccionario de Autoridades. En esta argumentación sigue Corominas la extensa disertación que a propósito del témino realizan Dozy y Engelmann, quienes recogen el sentido inicial de almohada elaborada con una estofa o paño grosero, de manera que el nombre del objeto sirvió después para denominar el tejido con el que se confeccionaba. Los autores reconocen que esta explicación no deja de ser una especulación que amplían para integrar la variedad de registros que acabó adquiriendo el término, convirtiéndose en una palabra polisémica y compleja de desentrañar en todos sus matices o variantes. DOZY, Reinarht y ENGELMANN, Wilhem; Glossaire des mots espagnols et portugais dérivés de l'arabe. Avec une introduction linguistique, un index de mots européens et un index arabe, Amsterdam, Apa. Oriental Press, 1982, pp. 158-159.

${ }^{37}$ A.H.P.Z., Juan Abad, 1504-1505, ff. 327r-330v; Juan de Arruego, 1519, folios sin numerar después del 176r

${ }^{38}$ A.H.P.Z., Miguel Villanueva, 1505, f. 349r; Luis Sora, 1509, f. 418v. Las carácterísticas de estos tejidos se explican en DÁVILA CORONA, Rosa Ma ${ }^{\mathrm{a}}$, DURÁN PUJOL, Monserrat y GARCÍA FERNÁNDEZ, Máximo, op.cit., pp. 55 y 203.

${ }^{39}$ A.H.P.Z., Luis Sora, 1521, f. 63v y 236r; Juan Burges, 1527, folios sin numerar después del 29r; Juan Díaz de Altarriba, 1527, folios sin numerar; Juan de Arruego, 1530, f. 404v (referenciado por GÓMEZ URDÁÑEZ, Carmen, op. cit., p. 141); Juan Campi, 1540, f. 440r y 1547, ff. 58r-59r; Cristóbal Navarro, 1562, ff. 579r y $585 \mathrm{v}$.

${ }^{40}$ LATAS, Dabí, Diccionario Histórico Textil- Jacetania y Alto Gállego- Tejidos, indumentarias y complemento en el Viejo Aragón, Zaragoza, Prames, 2014, p. 208.

${ }^{41}$ WRIGHT, Lawrence, op. cit,pp. 73-74 y DIBIE, Pascal, op. cit., p. 70

${ }^{42}$ Muy interesante resulta el análisis de Corominas sobre el origen y evolución del término. Señala que el vocablo pasó al castellano antiguo como matalafe y al occitano antiguo almatrac, matalàs, fr. matelas (materas h. 1300). En Italiano dio lugar a la denominación materassa o materasso: COROMINAS, Joan, op. cit., A-CA, Tomo I, pp.182-183. Coincide Pascal Dibie para quien el término materas, palabra que en francés aparecería ya en el siglo XIII, procede del árabe mátrah, y servía para designar un colchón relleno con lana o algodón, sobre el que se superponía otro de plumas llamado couste, coute, coite, couette. DIBIE, Pascal., op. cit., p. 70. Este mismo autor habla del empleo de la voz "chevecel" o "chevecier", equivalentes al castellano cabezal, que dio lugar a "chevez" en el siglo XIII y a "chevet" en la centuria siguiente. Se utilizaba para denominar la parte de la cama donde se apoya la cabeza y la propia cabecera del lecho. Se usó hasta la época de Montaigne, para ser sustituida después por "oreiller".

${ }^{43}$ Ibidem., pp. 182-183

${ }^{44}$ A.H.P.Z., Miguel Villanueva, 1505, f. 305r y 1510, f. 399r; SERRANO Y SANZ, Manuel, op. cit., Año II, Tomo II, Diciembre 1915, p. 710.

${ }^{45}$ SERRANO Y SANZ, Manuel, op. cit., Año II, Tomo II, Junio 1915, Cuaderno VIII, p. 342; A.H.P.Z., Miguel Villanueva, 1505, f. 271r.

${ }^{46}$ COVARRUBIAS, Sebastián, op. cit., p. 67; A.H.P.Z., Miguel Villanueva, 1510, f. 399r. 
${ }^{47}$ A.H.P.Z., Juan Abad, 1504-1505, ff. 327r, 328r, 330r.

${ }^{48}$ SERRANO y SANZ, Manuel, op.cit., Año IV, Tomo IV, Abril 1917, Cuaderno XVII, p. 216. Este autor cita el El Itinerario de Ruy González de Clavijo, donde aparece uno de estos almadraques confeccionados en seda y bordado con hojas de roble y florecillas, entre otros motivos. Ibidem., Año II, Tomo II, Junio 1915, Cuaderno VIII, p. 342.

49 Ibidem., p. 342; Año II, Tomo II, Octubre 1915, Cuaderno IX, p. 556; Año II, Tomo II, Diciembre 1915, Cuaderno IX, p. 710; Año III, Tomo III, Abril 1916, Cuaderno XII, p. 224; Año IV, Tomo IV, Junio 1917, Cuaderno XVIII, p. 351 (En esta página recoge Serrano y Sanz el inventario de los bienes de doña Sevilla de Luna, y en el mismo figura "Otro almadrach, de la una part de listas d'armas Reales y de la otra part de listas cardenas y blancas")

${ }^{50}$ Diccionario de Autoridades, Tomo II, Letra C, p. 25 y Tomo VI, Letra O-Z p. 344; ALONSO, Martín, Diccionario medieval español. Desde las Glosas Emilianenses y Silenses ( $s$. X) hasta el siglo XV, Salamanca, Universidad Pontificia de Salamanca, 1986, Tomo I, A-C, p. 571. Covarrubias señala que el cabezal, "cuando es labrado y de gente de ciudad, se llama travesero": COVARRUBIAS, Sebastián, op. cit., p. 223. Sobre el término en francés DIBIE, Pascal, op. cit., p. 71.

${ }^{51}$ Definición de flujel en Diccionario de Autoridades, Tomo III, Letras D-Ñ, p. 770. Las características de los tejidos con los que se confeccionaba el travesero se explican con mayor detalle en DÁVILA CORONA, Rosa Ma , DURÁN PUJOL, Monserrat y GARCÍA FERNÁNDEZ, Máximo, op.cit., pp. 29, 91, 104, 171. Referencias documentales al uso de estas telas en: A.H.P.Z., Luis Sora, 1509, f. 466v; Juan Arruego, 1530, f. 406v; Cristóbal Navarro, 1562, ff. 570v y 578r; Agustín Casales, 1572, f. 950v.

${ }^{52}$ SÁNCHEZ CANTÓN, Francisco Javier, op. cit., p. 215.

${ }^{53}$ A.H.P.Z., Ximeno Gil, 113, f. 26v; Juan Abad, 1504-1505, ff. 325v; Juan Arruego, 1530, f. 406v.

${ }^{54}$ A.H.P.Z., Juan Abad, 1504-1505, f. 328r; Luis Navarro, 1520, folios sin numeras a partir del 39v; Joan Campi, 1540, f. 444v; Cristóbal Navarro, 1562, f. 570v; Agustín Casales, 1572, f. 946v y 950v; Cristóbal Navarro, 1581, f. 947r; Jerónimo Andrés, mayor, 1585, 529v, 531rJerónimo Andrés, menor, 1590, f. 1.191v; Juan de Escartín, 1596, 258v; Pablo Villanueva, 1599, folios sin numerar a partir de 770r. La descripción de los traveseros de Felipe II figura en SÁNCHEZ CANTÓN, Francisco Javier, op. cit., p. 215

${ }^{55}$ SÁNCHEZ CANTÓN, Francisco Javier, op. cit., p. 215. En inventarios aragoneses se citan estos aciruelos formando conjunto con otras almohadas más grandes y traveseros. A.H.P.Z., Cristóbal Navarro, 1562, f. 570v; Jerónimo Andrés mayor, 1585, ff. 512v, 425r, 526v y 529v; Pablo Villanueva, 1599, folios sin numeras a partir de 770r. La palabra acerico aparece en la documentación aragonesa en el siglo XVII: A.H.P.Z., Nicolás Cascarosa, 1631, f. 561v y 564v.

${ }^{56}$ De hecho, Corominas explica que acerico es un diminutivo de hacero, castellano antiguo, facero, derivado de FAZ, cara. Se llamó así el acerico o aceruelo porque servía para apoyar la cara, comparable al francés oreiller "almohada", derivado de oreille, oreja. COROMINAS, Joan, A-CA, Tomo I, p. 34. Martín Alonso explica el origen de este término de la misma forma: Martín ALONSO, Enciclopedia del Idioma .... Tomo I, p. 61.

${ }^{57}$ SERRANO Y SANZ, Manuel, op. cit., Año II, Tomo II, Octubre 1915, Cuaderno IX, p. 558. FERRANDIS, José, op. cit., pp. 110 y A.H.P.Z., Ximeno Gil, 1523, f. 139v; Juan Díaz de Altarriba, 1527, folios sin numerar; Miguel Español, 1552, folios sin numerar; Miguel Villanueva, 1510, f. 393r.

${ }^{58}$ DIBIE, Pascal, p 71; COROMINAS, Joan, CE-F, Tomo II, p. 129.

59 En el inventario de los bienes del rey Felipe II figuran varias almohadillas de color adornadas con ricas labores de bordado y encaje: SÁNCHEZ CANTÓN, Francisco Javier, op. cit., pp. 217-218; WRIGHT, Lawrence, op. cit., p. 74. Dibie menciona el uso de almohadillas perfumadas desde la Edad Media en Francia. DIBIE, Pascal. op. cit., pp. 71-72.

${ }^{60}$ ONIEVA, Mariano, Sueños y Ensueños. Muebles y ajuares en la alcoba del XIX, Zaragoza, Ibercaja, 2004, p. 16.

${ }^{61}$ COROMINAS, Joan, Volumen V, RI-X, pp. 104-105; A.H.P.Z., Francisco Sebastián, 1556, folios sin numerar a partir del 141r (referenciado por GÓMEZ URDÁÑEZ, Carmen, op. cit., p. 142); Juan Escartín, 1596, f. $234 \mathrm{v}$.

${ }^{62}$ DIBIE, Pascal, op. cit., p. 70; LATAS, Dabí, op. cit., p. 194.

${ }^{63}$ A.H.P.Z, Miguel Villanueva, 1504, f. 442v;1505, ff. 361r-362r; 1509, folios sin numerar a partir del 418v y 1510, f. 388v, 391r; 393r; Ximeno Gil, 1512, ff. 386v, 390v, 396r y 1513, ff. 27r y v; Luis Sora, 1522, f. 83r; Joan Campi, 1540, f. 445r; Agustín Casales, 1566, f. 608r y 1572, f. 953r; Jerónimo Andrés, mayor, 1585 , f. 
644v. Para profundizar en las características de algunos de estos tejidos, como el nabal o el brin puede consultarse DÁVILA CORONA, Rosa Mª , DURÁN PUJOL, Monserrat y GARCÍA FERNÁNDEZ, Máximo, op.cit., p. 45 y LATAS, Dabí, op. cit., pp. 68, 225.

${ }^{64}$ Esta alusión se encuentra en A.H.P.Z., Luis Sora, 1509, f. 467r (referenciado por GÓMEZ URDÁÑEZ, Carmen, op. cit., p. 140). Sábanas con decoraciones de randas se recogen en A.H.P.Z., Miguel Villanueva, 1505, f. 306r y 1510, f. 393r; Luis Sora, 1521, f. 237v, Ximeno Gil 1512, ff. 395v y 397r. Corominas explica la etimología de la palabra randa, que derivaría de de randa "extremo, fin", "cercado", de origen incierto, quizá céltico. Habla de la existencia en alemán del vocablo rant "borde del escudo", por lo que supone que RANDS o quizá más bien RANDO o RANDA existiera en gótico con el sentido de "borde". Corominas señala que que desde "extremidad, borde" se pudo pasar a "encaje", puesto que los encajes se ponen en el borde u orla de las prendas de ropa. Denominaciones como la castellana puntillas, la catalana puntes o la alemana spitzen aluden a lo mismo y más claro es todavía el neerlandes kant "encajes", canto, borde. Sin embargo, el propio Corominas es consciente de la existencia de puntos oscuros que el desarrolla de una forma más detallada y que no se recogen, pues se centran en aspectos etimológicos que transcienden el enfoque de este trabajo: COROMINAS Joan, op. cit., O-Z, Tomo V, p. 488.

${ }^{65}$ Unas sábanas con randas negras estrechas en A.H.P.Z., Miguel Villanueva, 1505, f. 306r. Sábanas de colores en A.H.P.Z., Jerónimo Andrés, mayor, f. 644v. Para profundizar en el predominio del color blanco a partir de 1850 y su contenido simbólico puede consultarse ONIEVA, Mariano, op.cit, p. 35.

${ }^{66}$ Diccionario de Autoridades, Tomo II, letra C, p. 406. Pottier también considera que una cocedra sería una almohada o colchón de plumas: POTTIER, Bernard, op. cit, p. 131.

${ }^{67}$ A.H.P.Z., Luis Sora, 1509, f. 481v. ((referenciado por GÓMEZ URDÁÑEZ, Carmen, op. cit., p. 142); Agustín Casales, 1566, f. 609v. Frecuentes son las referencias a estas colcedras o cocedras en los inventarios, en los que se señala, por lo general, que estaban rellenas de pluma o flujel: SERRANO y SANZ, Manuel, op. cit., Año IX, Tomo X, Abril 1922, Cuaderno XLII, p. 266; y 269; A.H.P.Z., Juan Abad, 1504-1505, f. 321v; Luis Sora, 1527, 247r; Agustín Casales, 1572, f. 954r.

${ }^{68}$ SARTI, Raffaella, op. cit., p. 159.

${ }^{69}$ FERRANDIS, José, op. cit., p. 341.

${ }^{70}$ ABAD-ZARDOYA, Carmen, "Por tierra y mar. El ajuar de camino como proyección del espacio doméstico", Res mobilis, Vol. 1, $\mathrm{n}^{\circ}$ 1, Oviedo, 2012, p. 44.

${ }^{71}$ Ibidem., p. 109; SERRANO y Sanz, Manuel, op. cit., Año III, Tomo III, Abril 1916, Cuaderno XII, p. 224.

${ }^{72}$ La refencia a esta cortapisa aplicada a un delantecama se halla en A.H.P.Z., Juan Arruego, 1511, folio sin numerar a partir de 386r. Sobre la courtepointe francesa puede consultarse a DIBIE, Pascal, op. cit., p. 71. Joan Corominas hace una extensa disertación acerca de la voz cortapisa y cortapeu en su diccionario. Asimismo, relaciona estos nombres con la colcha basteada que en francés se llamó courtepointe. Todas estas voces procederían, en su opinión del latín "cǔlcǐta pinsa" que vendría a significar "colchón apretado con bastas", como explica de forma extensa, si bien manifestando algunas dudas que considera podrían resolverse con un estudio más detallado de la colchonería en las postrimerías de la Edad Media. Las citas documentales que se han incluido en el texto parecen indicar que, efectivamente la suposición de que cortapisa y cortapeu fueron un tipo de cubierta es acertada. COROMINAS, J, CE-F, Tomo II, pp. 212-213.

${ }^{73}$ Las referencia a "frazada" o "marca mayor" puede consultar Diccionario de Autoridades, op.cit., Tomo III, DF, p. 793. Son numerosos los inventarios en los que se alude a mantas y licheras y se especifican sus carácterísticas: A.H.P.Z., Juan Abad, 1504-1505, f. 327r; Miguel Villanueva, 1504, f. 276r, 1505, ff. 360v; 422v, 424v y 427v, 1510, f. 392r; Ximeno Gil, 1513, ff. 26 r y v y 27v; Luis Sora, 1521 f. 63v; Juan Díaz de Altarriba, 1527; Martín Blancas, 1534, ff. 173v y 175r; Pedro López, 1548, f. 583r ((referenciado por GÓMEZ URDÁÑEZ, Carmen, op. cit., p. 140); Agustín Casales, 1572, f. 1248r; Jerónimo Andrés, mayor, 1585, f. 638v; Pablo Villanueva, 1599, f. 523r.

${ }^{74}$ COROMINAS, Joan, op. cit., Tomo VI, RI-X, pp. 738-739; Diccionario de Autoridades, op. cit., Tomo I, AB, p. 546; LATAS, Dabí, op. cit., p. 51; POTTIER, Bernard, op. cit., p. 108.

${ }^{75}$ SERRANO y SANZ, Manuel, op. cit., Año II, Tomo II, Junio 1915, Cuaderno VIII, p. 343; A.H.P.Z., Juan Abad, 1504-1505, f. 322r; Miguel Villanueva, 1504, f. 442v ((referenciado por GÓMEZ URDÁÑEZ, Carmen, op. cit., p. 140); 1505, ff. 360v, 423v, 424r; 1509, folios sin numerar a partir de 418v; 1510, ff. 391r y 392r; Juan Arruego, 1518, folios sin numerar a partir de 89r; Luis Navarro, 1520, folios sin numerar a partir de 39v; Luis Sora, 1522 , ff. 81v, 82v y 85v; 1526, ff. 92v y 93v; Joan Campi, 1547, f. 64r. Las características de algunas de 
las telas utilizadas en la cofección de vanovas pueden cosultarse en: DÁVILA CORONA, Rosa Ma , DURÁN PUJOL, Monserrat y GARCÍA FERNÁNDEZ, Máximo, op.cit., pp. 52, 59-60, 65-66.

${ }^{76}$ Diccionario de Autoridades, Tomo II, letra C, pp. 406-407; ABAD-ZARDOYA, Carmen, op. cit., p. 106.

${ }^{77}$ FERRANDIS, José, op. cit., pp. 341-342; SÁNCHEZ CANTÓN, Francisco Javier, op. cit., pp. 213-214; A.H.P.Z., Miguel Villanueva, 1509, folios sin numerar a partir de 418v; Luis Sora, 1514, folios sin numerar a partir de 643r; Juan de Altarriba, 1527, folios sin numerar; Jimeno Sanz del Villar, 1535, ff. 561r, 562r; Agustín Casales, 1566, ff. 346v, 607r, 609v; Cristóbal Navarro, 1581, ff. 492r, 496v; Jerónimo Andrés mayor, 1585, f. 432v; Pablo Villanueva, 1599, folios sin numerar a partir de 770r.

${ }^{78}$ Inventario recogido por FERRANDIS, José, op. cit., p.112. Ejemplos de rodapiés y delantecamas decorados en A.H.P.Z., Juan de Arruego, 1530, f. 406v; Jimeno Sanz del Villar, 1535, f. 566r. La palabra rodapié fue definida en el Diccionario de Autoridades, O-Z, Tomo V, p. 629. Carmen Abad recoge este mismo sentido y señala el papel del rodapié a la hora de proteger de roces y suciedad. ABAD-ZARDOYA, Carmen, op. cit., pp. 106-107.

Fecha de recepción: 16 de octubre de 2016

Fecha de revisión: 9 de diciembre de 2016

Fecha de aceptación: 22 de diciembre de 2016 